\title{
Ilse Korotin, Edith Stumpf-Fischer (Hg.): Bibliothekarinnen in und aus Österreich. Der Weg zur beruflichen Gleichstellung (= bio- grafia - Neue Ergebnisse der Frauenbiografieforschung 25, hg. v. Ilse Korotin), Wien: Praesens Verlag 2019. 792 S., zahlr. Abb. ISBN 978-3-7069-1046-0, EUR 49,00.-
}

Der gefertigte Rezensent durfte an anderem Ort schon generell darauf verweisen, dass eine Besprechung eines Lexikons bzw. überhaupt eines Sammelbandes, gar nicht so einfach ist, wie es vielleicht scheinen könnte. Und doch geht einem bei der Lektüre und der weiteren Arbeit an derartigen Buchprodukten der Impetus durch, den Text für eine breitere Publikumsschicht zu "analysieren" und so schmackhaft zu machen, dass sich nicht nur die Buchhändlergilde freut, sondern vor allem die Autorinnen und Autoren den wichtigen Nachweis erhalten, dass ihre Arbeit keineswegs überflüssig war/ist.

Der vorliegende Band teilt sich in zwei große Abschnitte, einerseits in übergreifende

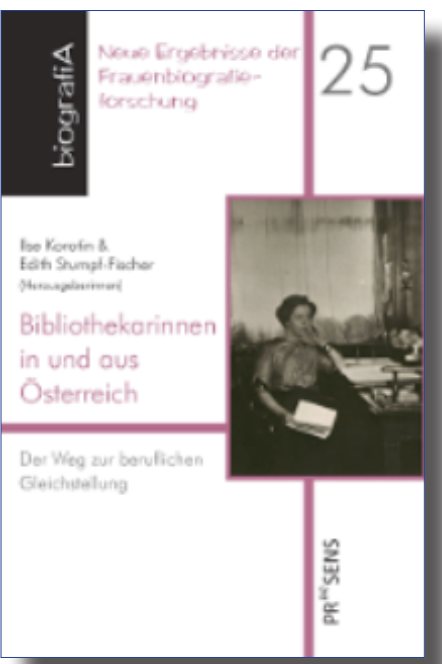
Berichte zum Gesamttitel, andererseits in lexikalisch aufbereitete Biografien von Bibliothekarinnen in Vergangenheit und Gegenwart. Für den letzteren Block seien die gründlichen Recherchen im Archivbereich besonders hervorgehoben, eine Tatsache, die heute des Öfteren auch im Bereich der Wissenschaft mehr als vernachlässigt wird. Kleinigkeiten der zu aktualisierenden Biografien werden sicherlich in einer weiteren Auflage, die für derartige Werke einfach verpflichtend sind, Ergänzungen/Ausbesserungen erfahren.

$\mathrm{Zu}$ diesen präzise erarbeiteten und gut lesbaren Biografien von Bibliothekarinnen seit dem 12. Jahrhundert (!) bis heute, fügen sich die an den Beginn des Lexikons gesetzten Beiträge zu übergreifenden Themen des Berufs der Bibliothekarin. Dabei spannt sich auch hier der Bogen von den Frauenklöstern des Mittelalters über die Frage von Kinderbibliotheken, zu religiösen Volks- und Fachbüchereien und „parteipolitisch“ ausgerichteten Bibliotheken. Hier kommt es erstmals zur Aufarbeitung der verschiedensten Dienststellen und außerdem zu sehr oft die lexikalischen Beiträge wertvoll ergänzenden Biographien einzelner Protagonistinnen. Dem Exil, 
zu dem nicht wenige Bibliothekarinnen gezwungen wurden, oder die auch aus Überzeugung Österreich verließen, ist ebenso Augenmerk gewidmet, wie den großen einschlägigen staatlichen Einrichtungen (Nationalbibliothek, Universitatsbibliothek, Administrative Bibliothek etc.). Der Band, der, wie schon angedeutet, bis in die Jetztzeit führt, zeigt naturlich auch das Wirken der Bibliothekarinnen im Bereich der EDV-Anwendungen auf und ihre Bedeutung im Rahmen der immer wieder Veränderungen unterworfenen Ausbildungsfrage für diesen Beruf.

Den Abschluss dieses Blockes, dem das Lexikon folgt, bildet ,Die Bibliothekarin in der österreichischen Literatur und im Film' mit mehr als interessanten, oftmals vergessenen Beispielen zu dieser Thematik.

Die Texte, aus einem Projekt hervorgegangen, stellen eine einmalige Arbeit dar, zu der allen (!) Beteiligten nur gratuliert und vor allem gedankt werden muss.

Eine Publikation, die eigentlich in keiner, auch der kleinsten Bibliothek fehlen sollte. Die Lektüre erfreut, erschüttert, belehrt und vieles mehr.

Der Rezensent, dem vieles Bekanntes begegnete, aber eben so viel, wenn nicht sogar mehr Neues, empfiehlt den Band allen an osterreichischer Bibliotheksgeschichte Interessierten zur Pflichtlektüre.

\section{GenDir. i.R. Hon.-Prof. Dr. Lorenz Mikoletzky E-Mail: lorenz.mikoletzky@oesta.gv.at}

DOI: https://doi.org/10.31263/voebm.v73i1.3426

(C) Lorenz Mikoletzky

Dieses Werk ist - exkl. einzelner Logos und Abbildungen - lizenziert unter einer Creative-Commons-Lizenz Namensnennung 4.0 International 